\title{
Higher prevalence of permanent congenital hypothyroidism in the Southwest of Iran mostly caused by dyshormonogenesis: a five-year follow-up study
}

Majid Aminzadeh'

'Division of Pediatric Endocrinology and Metabolism, Pediatric Department, School of Medicine, Ahvaz Jundishapur University of Medical Sciences, Ahvaz, Iran

\section{Correspondence to:}

Majid Aminzadeh

Abuzar Children's Hospital

Pasdaran Blvd, Ahvaz, Iran

aminzadeh_m@ajums.ac.ir

Received on Nov/12/2017 Accepted on May/30/2018

DOI: 10.20945/2359-3997000000085

\begin{abstract}
Objective: The incidence of congenital hypothyroidism $(\mathrm{CH})$ varies globally. This 5 -year study aimed to determine the prevalence of permanent $\mathrm{CH}$ in the southwest of Iran. Materials and methods: Between January 2007 and December 2009, all newborns in Ahvaz, the biggest city in the southwest of Iran, were screened for $\mathrm{CH}$ using a heel-prick sample for thyrotropin (TSH) levels. Subjects with $\mathrm{TSH} \geq 5 \mathrm{mU} / \mathrm{L}$ were evaluated for T4-TSH. Infants with T4 $<6.5 \mu \mathrm{g} / \mathrm{dL}, \mathrm{TSH}>10 \mathrm{mU} / \mathrm{L}$, and normal T4 but persistent ( $>60$ days) high TSH were considered to have $\mathrm{CH}$. After the third birthday, treatment was discontinued, andT4-TSH was reevaluated; subjects with TSH $\geq 10 \mathrm{mU} / \mathrm{L}$ were investigated using thyroid Tc99 scintigraphy (TS). Based on TS, they were classified as normal, dysgenetic, or athyretic (agenesis). Results: Screening was performed for 86,567 neonates, and 194 were confirmed to have $\mathrm{CH}$ (100 males; $\mathrm{F} / \mathrm{M}=0.94$; overall incidence $1: 446)$. After the third birthday, reevaluation was performed in all (except 18 that were not accessible). From 176 patients, 81 (46\%) were diagnosed with permanent $\mathrm{CH}$, and 95 were discharged as transient. Considering the same percentage in the lost cases, the prevalence of permanent $\mathrm{CH}$ was found to be 1:970. TS performed for 53 of the permanent subjects found agenesis/dysgenesis in 25 (F:M = 15:10) and a normal result in 28 (F:M $=11: 17)$, indicating dyshormonogenesis as the cause in more than $50 \%$ of subjects. Conclusions: The incidence of $\mathrm{CH}$ in this area was found to be higher than that in other countries but less than the incidence rate reported in central Iran. The large number of transient cases of $\mathrm{CH}$ suggests environmental or maternal causes for the incidence rather than a genetic basis. Arch Endocrinol Metab. 2018;62(6):602-8
\end{abstract}

Keywords

Congenital hypothyroidism; dyshormonogenesis; screening; Tc-99m thyroid scintigraphy; thyroid dysgenesis

\section{INTRODUCTION}

S creening for congenital hypothyroidism $(\mathrm{CH})$, one of the most common causes of preventable mental retardation, has been performed in developing countries since the 1960s, but it has been routinely conducted in Iran only since the year 2000 . The prevalence of $\mathrm{CH}$ has been reported to be $1 / 1,000$ to $1 / 370$ in Iran $(1,2)$, which is significantly higher than that of the American and European countries $(1 / 4,000)(3,4)$. The positive cost-benefit ratio of screening for $\mathrm{CH}$ ranges from 3.6:1 in developed countries (5) to 15:1 in developing countries such as Iran (6). Theoretically, dysgenesis, dyshormonogenesis, and iodine deficiency are the most common causes of $\mathrm{CH}$. Prenatal (iodinated disinfectants) and postnatal iodine exposure (milk iodine content) have also been implicated as etiologic factors $(7,8)$. Varying incidence of $\mathrm{CH}$ has been reported in different areas of Iran, with no data from the southwest regions of the country, which is different from central and northern Iran in terms of weather, altitude, and gene pool. Another difference between various areas of Iran is that the southwest regions of the country have a higher rate of consanguineous marriages than the other regions. The latest reported $\mathrm{CH}$ incidence of $1 / 370$ neonates in central Iran with a large number of transients (40\%) (9) was significantly higher than the incidence rate previously reported. Accordingly, we aimed to determine the prevalence of $\mathrm{CH}$ in the southwest of Iran using a more definite diagnostic algorithm in a large enough population and 
for a longer duration. The classic approach used herein may provide guidelines for diagnosing recalled (or referred) infants by a standard and safe algorithm (fully described in Materials and Methods and Table 1).

Table 1. Study protocol for decision-making in the screening program of $\mathrm{CH}$

\begin{tabular}{lccc}
\hline T4 $\mathbf{( g / d \mathbf { ~ } )}$ & TSH $^{\text {a }}$ (mU/L) & Decision & Follow-up \\
\hline$\geq 8.5$ & $<5.5$ & Discharge & None \\
$\leq 6.49$ & $\geq 10$ & Treatment & As a CH ${ }^{b}$ case \\
$6.5-9.9$ & $\geq 10$ & Suspected CH & TFT 2 wks later \\
$6.5-9.9$ & $5-9.9$ & Suspected CH & TFT 4 wks later \\
$\geq 10$ & $\geq 5$ & Suspected CH & TFT 4 wks later \\
Each level & $>6.0$ after 60 & Treatment & As a CH case \\
& day (10) & & \\
\hline
\end{tabular}

a Thyroid stimulating hormone (normal for 2-20 wks $=0.5-5.5$ ); ${ }^{\text {b }}$ congenital hypothyroidism.

\section{MATERIALS AND METHODS}

During the 3-year period from January 2007 to December 2009, all infants born in Ahvaz, the biggest city in the southwest of Iran, were enrolled (Table 2). This study was approved by the Ethical Committee of Ahvaz Jundishapur University of Medical Sciences. All neonates were screened before getting their identification card to ensure $100 \%$ compliance (however, some infants who did not pursue this policy were missed; Figure 1). Individuals who were born in Ahvaz but whose parents lived in other cities were excluded but were followed up on and treated if required. In all healthy and term babies, blood was obtained from a heel prick between the $3^{\text {rd }}$ and $5^{\text {th }}$ day of life and was collected on a filter paper for thyroid stimulating hormone (TSH) assessment using a kit (Padtan Elm Incorporation, Tehran, Iran) and an ELISA reader (Stat Fax 2100; Awareness Technologies, USA) by the same four staff members during the study period. For preterm infants and those who required postnatal hospitalization, testing was done after discharge but before the $30^{\text {th }}$ day of life. The subjects were notified before the $10^{\text {th }}$ day if the TSH level was $>5 \mathrm{mU} / \mathrm{L}$ and were referred for suspected $\mathrm{CH}$. Screening in this study was based

Table 2. Distribution of all screened newborns and $\mathrm{CH}$ patients, based on sex and year of birth

\begin{tabular}{llll}
\hline Year of birth $^{\mathbf{a}}$ & \multicolumn{1}{c}{$\mathbf{1}^{\text {st }}$} & \multicolumn{1}{c}{$\mathbf{2}^{\text {nd }}$} & \multicolumn{1}{c}{$\mathbf{3}^{\text {rd }}$} \\
\hline All newborns & $22209(51.2 \%)^{b}$ & $30021(50.5 \%)$ & $34337(52 \%)$ \\
CH subjects & $39(48.7 \%)$ & $85(48.2 \%)$ & $70(55.7 \%)$ \\
\hline
\end{tabular}

${ }^{a}$ During the study period; ${ }^{b}$ numbers in parenthesis show the percentage of males. on TSH measurement, so it may not have detected infants with delayed TSH elevation or with central or hypopituitary hypothyroidism (Figure 2). Infants with TSH $>5 \mathrm{mU} / \mathrm{L}$ but $<9.99 \mathrm{mU} / \mathrm{L}$ were retested by a second heel prick and referred if the level remained $>5$ $\mathrm{mU} / \mathrm{L}$. Referred individuals were subjected to thyroid function tests (TFTs), including T4 and TSH, using a venous blood sample. The time line for performing the confirmatory TFT was chosen according to the TSH level observed in the first screening heel-prick test:

a. For TSH $<20 \mathrm{mU} / \mathrm{L}$, around the $21^{\text {st }}$ day.

b. For TSH between 20 and $39.9 \mathrm{mU} / \mathrm{L}$, around the $14^{\text {th }}$ day.

c. For $\mathrm{TSH} \geq 40 \mathrm{mU} / \mathrm{L}$, reassessed and treated on the same day of referral.

In the next years of screening, based on our national guidelines, the cutoff for emergency treatment was lowered to $\geq 20 \mathrm{mU} / \mathrm{L}$. The confirmatory test was performed by venipuncture at least 2 hours after the last feeding in the morning. We used an ELISA kit (Monobind, USA) and an ELISA reader (BioTek ELx800, USA) to confirm or rule out $\mathrm{CH}$ among the referred suspected neonates. Dealing with the final laboratory results was done according to the protocol of the screening department of the Ministry of Health. This protocol was used with a more definite and detailed algorithm matching international standards so as to avoid unnecessary treatment of transient hyperthyrotropinemia (<2 months) and to make treatment decisions for infrequent situations (Table 1). All referred suspected infants were followed up on until the final diagnosis was made: the beginning of treatment for $\mathrm{CH}$ or until the normalization of thyroid function in transient hyperthyrotropinemia.

The aim was to begin replacement therapy with levothyroxine before the $30^{\text {th }}$ day of life. The $\mathrm{CH}$ subjects younger than 6 months were followed up on monthly, between the $6^{\text {th }}$ and $12^{\text {th }}$ month, bimonthly, and after that, until the $36^{\text {th }}$ month, quarterly. The goal was to maintain T4 at $>8 \mu \mathrm{g} / \mathrm{dL}$, and TSH between 0.5 and $2.0 \mathrm{mU} / \mathrm{L}$, based on the mean normal range (10-12), with normal growth and development. The treatment was stopped earlier than 3 years only if the subjects required $<12.5 \mu \mathrm{g} /$ day of levothyroxine $(1 / 4$ of a $100 \mu \mathrm{g}$ tablet, every other day) to stay in a euthyroid state. These subjects were classified as transient $\mathrm{CH}$. Subclinical hypothyroidism was defined in the subjects who had normal T4 levels but persistent high TSH $(5.5-15 \mathrm{mU} / \mathrm{L})$ after the $60^{\text {th }}$ day $(13,14)$. The patients 
in whom treatment could be discontinued before 6 months $(\mathrm{n}=2)$ were also classified as transient. However, classification of this group of subjects as transient high TSH would be more appropriate. To compare the final outcome based on the primary diagnostic TSH levels, all cases were classified into three groups: 1$) \geq 40 \mathrm{mU} / \mathrm{L}$; 2) 20-39.9 mU/L; and 3) 5-19.9 mU/L (Table 3).

After the third birthday, replacement therapy was discontinued for 1 month, then T4 and TSH assessments were performed in all subjects as reevaluation. Any rise of TSH to $\geq 10 \mathrm{mU} / \mathrm{L}$ in each test after discontinuation (also in those labeled as transient aged $\leq 3$ years) was classified as permanent disease and was followed by thyroid scintigraphy (TS) and re-initiation of levothyroxine therapy. If the T4 and TSH concentrations were in the reference range, euthyroidism was assumed, and a diagnosis of transient hypothyroidism was recorded. On the basis of the TS results, thyroid disorders were classified as agenesis (absence of thyroid on scan), dysgenetic (ectopia, thyroglossal cyst, lingual, hypoplasia, hemiagenesis, small thyroid, etc.), or dyshormonogenesis (normal scan or diffuse goiter; Figure 3). All those who could leave the treatment before 3 years of age or after the third year (after reevaluation) were followed up on for at least 24 months to distinguish between those with actual transient $\mathrm{CH}$ versus permanent subclinical hypothyroidism $(\mathrm{TSH} \geq 10 \mathrm{mU} / \mathrm{L})$. Data were presented after 5-year follow-up of all permanent and transient subjects (total 8-year duration of the study) to find the exact prevalence. Because most TSH results were reported in approximation ( $>40$ or $>100$ ), the TSH ranges, rather than means, were used to compare the outcomes.
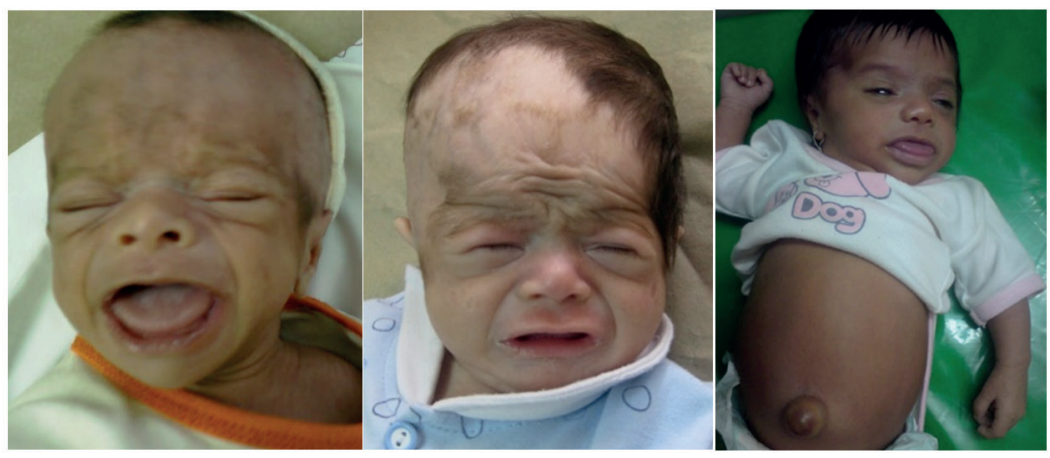

Figure 1. Three cases of congenital primary hypothyroidism were missed because of parental negligence, referred at 3 months with developmental delay.

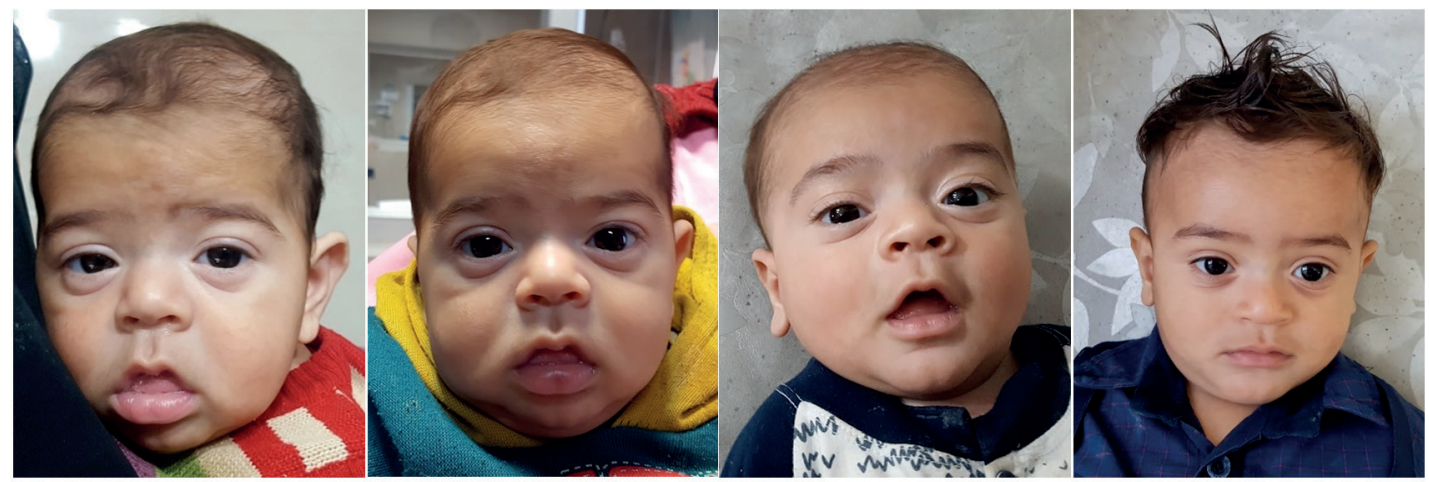

Figure 2. A 6-month-old infant referred with poor growth diagnosed as congenital central hypothyroidism. He was missed because of screening with TSH. Serial photos (left to right: at the time of diagnosis, 1 week, 4 weeks, and 6 months after treatment) clearly show the facial changes as a reliable marker of clinical response over time.

Table 3. Final outcome in 194 cases of $\mathrm{CH}$ according to their first serum TSH

\begin{tabular}{lcccccccc}
\hline TSH $^{\boldsymbol{*}}$ & Permanent; $\mathbf{n}(\%)$ & F:M & Transient; $\boldsymbol{n}$ (\%) & F:M & Unknown; $\boldsymbol{n}$ (\%) & F:M & Total; $\mathbf{n}(\%)$ & F:M \\
\hline$\geq 40$ & $56(52) \dagger$ & $30: 26$ & $39(36)$ & $19: 20$ & $13(12)$ & $6: 7$ & $108(100)$ & $55: 53$ \\
$20-39.9$ & $10(25.5)$ & $4: 6$ & $25(64)$ & $11: 14$ & $4(10.5)$ & $2: 2$ & $39(100)$ & $17: 22$ \\
$<20$ & $15(32)$ & $6: 9$ & $31(66)$ & $15: 16$ & $1(2)$ & $1: 0$ & $47(100)$ & $22: 25$ \\
Total & $81(42)$ & $40: 41$ & $95(49)$ & $45: 50$ & $18(9)$ & $9: 9$ & $194(100)$ & $94: 100$ \\
\hline
\end{tabular}

*mU/L; $†$ percent of outcome in each TSH group. 


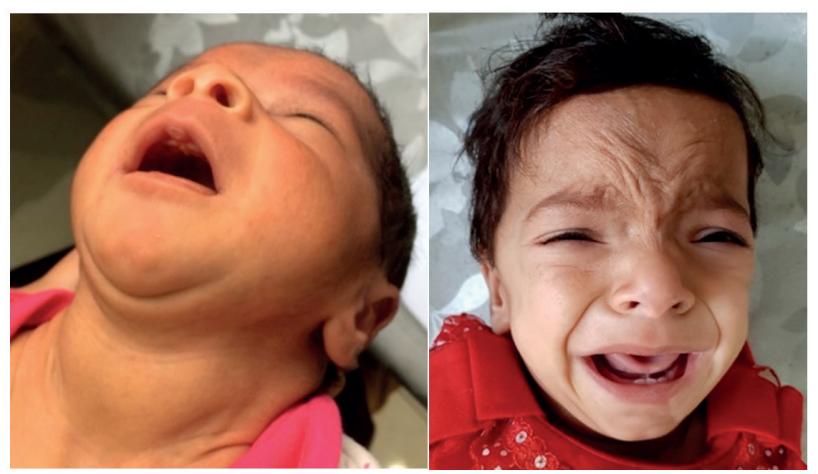

Figure 3. A neonate with goiterous congenital primary hypothyroidism (negative history of maternal thyroid disorder or perinatal risk factor) indicating dyshormonogenesis. She came back after 2 years because of developmental delay. She had a TSH > $100 \mathrm{mU} / \mathrm{L}$ due to not taking medication.

\section{Statistics}

Data were analyzed using SPSS version 16.0 (SPSS Inc., Chicago, IL, USA), and the logistic regression test was used to analyze risk prediction in each outcome. $P$ values $<0.05$ were considered statistically significant.

\section{RESULTS}

During the 3 years of screening, 86,567 neonates (51.28\% male) were screened, of whom 5,923 (6.8\%) had TSH levels $\geq 5 \mathrm{mU} / \mathrm{L}$. Those with $\mathrm{TSH} \geq 10$ $\mathrm{mU} / \mathrm{L}$ were referred directly, but a majority of them $(\mathrm{n}=5,039 ; 85 \%)$, who had TSH values between 5 and $9.99 \mathrm{mU} / \mathrm{L}$, were reassessed by the heel-prick method and then referred if the second test also revealed TSH to be $>5 \mathrm{mU} / \mathrm{L}$ (final recall rate referred on suspicion of $\mathrm{CH}=2.4 \%$; this means that up to 10 normal infants were recalled for testing for every 1 case of hypothyroidism). According to the acceptable definitions (Table 1), 194 cases (51.5\% male) were diagnosed as $\mathrm{CH}$ (both permanent and transient), requiring treatment. The overall incidence was $1: 446$ live births with a female/male $(\mathrm{F} / \mathrm{M})$ ratio of 0.94 . Table 2 shows the distribution by year of all live births and the prevalence of $\mathrm{CH}$ during the study period.

After the third birthday, all 176 diagnosed $\mathrm{CH}$ subjects underwent reevaluation (18 of 194 were missed because of two deaths, five immigrations, and loss of contact information for the rest) with 4 weeks levothyroxine discontinuation and serum T4 and TSH measurement. Based on the TSH (if it was $>10 \mathrm{mU} / \mathrm{L}$ in the first or follow-up tests), 81 (46\% of 176) subjects were diagnosed with permanent $\mathrm{CH}$
(F:M $=40: 41 ; 0.97$, similar to the ratio seen in all 194 $\mathrm{CH}$ cases, including both permanent and transient). The remaining 95 subjects were followed up on with TSH rechecks for at least 2 more years with intervals of 3,6 , and 12 (and 24 if needed) months to make sure that there was no rise of TSH. These patients were discharged as transient $\mathrm{CH}$. Considering the similar percentage of permanents in the missed group (46\%), we probably lost at least 8 (of 18 ) more permanent $\mathrm{CH}$ cases to follow. The final prevalence of permanent $\mathrm{CH}$ was calculated as 1:970.

The final outcomes were reviewed and compared in all cases based on their first diagnostic TSH values (Table 3 ). These data disclosed that 17 of 18 missed cases had TSH $>20 \mathrm{mU} / \mathrm{L}$. This means that we probably lost more than 8 permanent $\mathrm{CH}$ cases among the 18 missed cases, indicating a higher prevalence of $\mathrm{CH}$.

Compared to those who had TSH $<20 \mathrm{mU} / \mathrm{L}$ (subclinical $\mathrm{CH}$ ), the patients with $\mathrm{TSH} \geq 40 \mathrm{mU} / \mathrm{L}$ had at least three times more risk to be permanent (1.41-6.22; 95\% CI; OR). For those with TSH $=20$ $39.9 \mathrm{mU} / \mathrm{L}$, no significant risk was found (0.317-2.15; 95\% CI; OR).

TS performed in 53 of 81 permanents showed: agenesis in $5(\mathrm{~F}: \mathrm{M}=2: 3)$, dysgenesis in $20(\mathrm{~F}: \mathrm{M}=13: 7)$, and normal pattern in 28 ( $\mathrm{F}: \mathrm{M}=11: 17)$, indicating that $>50 \%$ of cases were caused by dyshormonogenesis. Details of the TS results are shown in Table 4.

Compared to those who had TSH $<20 \mathrm{mU} / \mathrm{L}$ (subclinical $\mathrm{CH}$ ), the patients with $\mathrm{TSH} \geq 40 \mathrm{mU} / \mathrm{L}$ had almost five times more risk of having agenesis or dysgenesis in TS (0.98-28.2; 95\% CI; OR). For those with $\mathrm{TSH}=20-39.9 \mathrm{mU} / \mathrm{L}$, no significant risk was found $(0.2-19.9 ; 95 \% \mathrm{CI}$; OR).

There were 11 subjects receiving treatment with the diagnosis of mild subclinical $\mathrm{CH}(\mathrm{TSH}=5.5-10)$. On reevaluation, four cases were found to be permanent: two boys (both normal scan) and two girls (one dysgenesis and one normal scan). The 7 other subjects were discharged as transient.

During this period, two cases of pan-hypopituitarism (normal ACTH, adrenocorticotropic hormone), two with genetically confirmed Pit-1 defect (deficiency of TSH, growth hormone, and prolactin), and one with isolated TSH deficiency (Figure 2) were also diagnosed independent of the screening program and were included in the overall prevalence without performing TS. 
Table 4. Comparison of the first serum TSH values in different etiologies of permanent $\mathrm{CH}$ based on TS

\begin{tabular}{lcccccccc}
\hline TS group & TSH $\geq \mathbf{4 0}$ & F:M & $\mathbf{2 0 - 3 9 . 9}$ & F:M & TSH $<$ 20 & F:M & Total & F:M \\
\hline Agenesis & $4(80) \dagger$ & $2: 2$ & $1(20)$ & $0: 1$ & $0(0)$ & $0: 0$ & $5(100)$ & $2: 3$ \\
Dysgenesis & $17(85)$ & $11: 6$ & $1(5)$ & $1: 0$ & $2(10)$ & $1: 1$ & $20(100)$ & $13: 7$ \\
Normal & $16(57)$ & $8: 8$ & $4(14.3)$ & $1: 3$ & $8(25)$ & $2: 6$ & $28(100)$ & $11: 17$ \\
Total & $37(69.8)$ & $21: 16$ & $6(11.3)$ & $2: 4$ & $10(18.8)$ & $3: 7$ & $53(100)$ & $27: 26$ \\
\hline
\end{tabular}

${ }^{*} \mathrm{mU} / \mathrm{L} ; \uparrow$ † percent of TSH group in each outcome.

\section{DISCUSSION}

In concurrence with previous reports, we observed a high prevalence of $\mathrm{CH}$ in our study, similar to other Asian populations. As per the Iranian Ministry of Health recommendation and our study design, we used TSH as the screening assay to evaluate $\mathrm{CH}$. This probably resulted in missing only 2 of $100 \mathrm{CH}$ cases (12), including those with secondary or tertiary hypothyroidism, infants with an absence of the free T4 feedback mechanism, and those with a delayed elevation of TSH levels. As mentioned above, we found 5 cases of central $\mathrm{CH}$ that their missing was unavoidable (Figure 2). Accordingly, the ideal screening method would be to evaluate primary TSH with T4, but it is cost-prohibitive.

As with most congenital disorders, the main causes of the differences in $\mathrm{CH}$ prevalence would be ethnicity, gene pool, and the rate of consanguineous marriages $(15,16)$. Similar to other Asian populations, our neonates are at a higher risk for $\mathrm{CH}$, although the main etiologic factors including dysgenesis or dyshormonogenesis were not very prevalent in our cases of $\mathrm{CH}$. In fact, similar to other Iranian studies (17), we found a high rate of transient $\mathrm{CH}$ cases (near half), which cannot be attributed to genetics but rather to maternal iodine supplementation and/ or thyroid status $(7,8)$. While early treatment of even transient subjects is mandatory to prevent any degree of neurodevelopment impairment, better management of iodine supplementation and maternal thyroid status can obviate a large number of recalls, unnecessary venipuncture, replacement therapy, clinic visits, and, more importantly, family stress and conflict.

After a 2-year follow-up of all those who could leave treatment before or after 3 years of age (including those with mild subclinical $\mathrm{CH}$; TSH $<10 \mathrm{mU} / \mathrm{L}$ ), we found a higher rate of transients than that previously reported in Isfahan $(9)(\approx 50 \%$ vs. $40 \%)$.

Tc-99m TS was reported to be a useful diagnostic tool for the investigation of suspected $\mathrm{CH}$ and can potentially help manage and predict the lifelong replacement therapy requirement (18). However, in the first 3 years of life, the treatment plan remains the same.

The prevalence of permanent $\mathrm{CH}$ was found to be about $1 / 970$ live births, which is less than the $1 / 750$ live births reported in Isfahan (9) but near to the 1/918 live births identified in Asian families living in England (19). Using a standard classic approach with a huge number of live births, the prevalence rate of $1 / 446$ (total of permanent and transient cases) found in our study supports the controversial report from central Iran showing a $\mathrm{CH}$ incidence of $1 / 370$ (2). The female-to-male ratio for all $\mathrm{CH}$ subjects in our study (0.94) was quite similar to that of the whole country $(20)$.

Additionally, many cases of permanent subclinical $\mathrm{CH}$ with seemingly normal TS results (except one with a right hemiagenesis) were identified in our study. Because the benefits of replacement therapy are significant even in adults (21), it is logical to treat and follow up on all subclinical $\mathrm{CH}$ cases, particularly those with $\mathrm{TSH} \geq 10 \mathrm{mU} / \mathrm{L}$. Although patients with TSH levels > $10 \mathrm{mU} / \mathrm{L}$ often have reduced free T4 levels and may have hypothyroid symptoms, theoretically, they must be clinically normal regarding the normal $\mathrm{T} 4$ levels. The high incidence of permanent subclinical $\mathrm{CH}$ in cases with normal T4 but mildly elevated TSH (5-10 $\mathrm{mU} / \mathrm{L}$ ) shows the importance of treatment and followup for such infants.

Interestingly, only permanent $\mathrm{CH}$ subjects with agenesis/dysgenesis in their scan had a female predominance, similar to what was discovered in $\mathrm{CH}$ subjects of Western countries (mostly caused by dysgenesis). The finding of a $\mathrm{F}: \mathrm{M} \approx \mathrm{l}$ in all subjects (permanent and transient cases) and a male predominance in the dyshormonogenesis group is compatible with their etiologic background. Transient $\mathrm{CH}$ subjects as a big part of total $\mathrm{CH}$ cases possibly caused by environmental factors should not have a 
sex difference. Dyshormonogenesis is almost always inherited in a recessive pattern, but only $2 \%$ of dysgenesis is familial (22). This may explain the F:M differences we discovered in two groups of thyroid dyshormonogenesis and thyroid dysgenesis.

In concordance with previous studies $(17,23)$, in our study, patients with permanent $\mathrm{CH}$ had higher TSH levels than transient ones during the neonatal period. This finding emphasizes the need for careful follow-up in those with TSH $\geq 40 \mathrm{mU} / \mathrm{L}$.

The limitations of this study include inexperienced laboratory technicians, health staff, and physicians, particularly in the first year of the study $(24,25)$; noncooperative hospitals; families who did not participate or who approached private clinics independently; and the inability to achieve $100 \%$ screening coverage. Table 2 displays the number of screened newborns, rather than live births, which may have resulted in underestimating the total number of $\mathrm{CH}$ cases, although this problem theoretically does not change the prevalence recorded by our study.

The strength of this study is that it determined the real percentage of transient $\mathrm{CH}$ cases and also identified those cases with permanent $\mathrm{CH}$ but normal TS with a high degree of accuracy.

In conclusion, the prevalence of $\mathrm{CH}$ in the southwest part of Iran was found to be much higher than that of the Western countries; however, it was less than that found in central Iran and similar to that seen in Asian families living in Western countries. Accordingly, due to the importance of replacement therapy for transient cases, adequate follow-up is necessary. The high incidence of transient cases suggests environmental and/or maternal causes, rather than a genetic basis for the $\mathrm{CH}$.

Acknowledgments: this study was performed as a research project (ID: U-87010) approved by the vice chancellor of the Research Center at Ahvaz Jundishapur University of Medical Sciences. The author would like to thank all the staff of the screening department in the East and West Health Centers of Ahvaz.

Disclosure: no potential conflict of interest relevant to this article was reported.

\section{REFERENCES}

1. Ordookhani A, Mirmiran P, Moharamzadeh M, Hedayati M, Azizi F. A high prevalence of consanguineous and severe congenital hypothyroidism in an Iranian population. J Pediatr Endocrinol Metab. 2004;17(9):1201-9.
2. Hashemipour M, Amini M, Iranpour R, Sadri GH, Javaheri N, Haghighi $\mathrm{S}$, et al. Prevalence of congenital hypothyroidism in Isfahan, Iran: results of a survey on 20,000 neonates. Horm Res. 2004;62(2):79-83.

3. Deladoey J, Belanger N, Vliet GV. Random variability in congenital hypothyroidism from thyroid dysgenesis over 16 years in Québec. J Clin Endocrinol Metab. 2007;92(8):3158-61.

4. Rastogi MV, LaFranchi SH. Congenital hypothyroidism. Orphanet J Rare Dis. 2010;5:17.

5. Gu X, Wang J, Ye J, Cheng X. [A cost-benefit evaluation of neonatal screening for phenylketonuria and congenital hypothyroidism]. Zhonghua Yu Fang Yi Xue Za Zhi. 2000;34(3):147-9.

6. Delavari AR, Ahmadi SY, Birjandi R, Mahdavi AR, Nejad AN, Dini $M$. Cost-benefit analysis of the neonatal screening program implementation for congenital hypothyroidism in I. R. Iran. Int J Endocrinol Metabol. 2006;4(2):84-7.

7. Ordookhani A, Pourafkari M, Mirmiran P, Neshandar-AsI I, Fotouhi F, Hedayati SM, et al. Etiologies of transient congenital hypothyroidism in Tehran and Damavand. Iran J Endocrinol Metabol. 2004;6(2):107-13.

8. Nasri P, Hashemipour M, Hovsepian S, Amini M, Heidari K, Sajjadi $\mathrm{SA}$, et al. Comparison of urine and milk iodine concentration among congenitally hypothyroid neonates and their mothers and a control group. Iran J Endocrinol Metabol. 2009;11(3):265-72.

9. Hashemipour M, Hovsepian S, Kelishadi R, Iranpour R, Hadian $\mathrm{R}$, Haghighi $\mathrm{S}$, et al. Permanent and transient congenital hypothyroidism in Isfahan-Iran. J Med Screen. 2009;16(1):11-6.

10. Lem AJ, de RijkeYB, vanToor H, de Ridder MA, VisserTJ, HokkenKoelega AC. Serum thyroid hormone levels in healthy children from birth to adulthood and in short children born small for gestational age. J Clin Endocrinol Metab. 2012;97(9):3170-8.

11. Hollowell JG, Staehling NW, Flanders WD, Hannon WH, Gunter EW, Spencer CA, et al. Serum TSH, T(4), and thyroid antibodies in the United States population (1988 to 1994): National Health and Nutrition Examination Survey (NHANES III). J Clin Endocrinol Metab. 2002;87(2):489-99.

12. American Academy of Pediatrics, Rose SR; Section on Endocrinology and Committee on Genetics, American Thyroid Association, Brown RS; Public Health Committee, Lawson Wilkins Pediatric Endocrine Society, Foley T, Kaplowitz PB, Kaye $\mathrm{Cl}$, Sundararajan S, Varma SK. Update of newborn screening and therapy for congenital hypothyroidism. Pediatrics. 2006;117(6):2290-303.

13. Gillet M. Subclinical hypothyroidism: subclinical thyroid disease: scientific review and guidelines for diagnosis and management. Clin Biochem Rev. 2004;29(3):191-4.

14. Surks MI, Ortiz E, Daniels GH, Sawin CT, Col NF, Cobin RH, et al. Subclinical thyroid disease: scientific review and guidelines for diagnosis and management. JAMA. 2004;291(2):228-38.

15. Hall SK, Hutchesson AC, Kirk JM. Congenital hypothyroidism, seasonality and consanguinity in the West Midlands, England. Acta Paediatr. 1999;88(2):212-5.

16. Hashemipour M, Amini M, Talaie M, Kelishadi R, Hovsepian $\mathrm{S}$, Iranpour $\mathrm{R}$, et al. Parental consanguinity among parents of neonates with congenital hypothyroidism in Isfahan. East Mediterr Health J. 2007;13(3):567-74.

17. Karamizadeh Z, Dalili S, Sanei-far $H$, Karamifard $H$, Mohammadi $H$, Amirhakimi G. Does congenital hypothyroidism have different etiologies in Iran? Iran J Pediatr. 2011;21(2):188-92.

18. Iranpour R, Hashemipour M, Amini M, Talaei SM, Kelishadi $R$, Hovsepian S, et al. [Tc]-99m thyroid scintigraphy in congenital hypothyroidism screening program. J Trop Pediatr. 2006;52(6):411-5.

19. Rosenthal M, Addison GM, Price DA. Congenital hypothyroidism: increased incidence in Asian families. Arch Dis Child. 1988;63(7):790-3. 
20. Veisani Y, Sayehmiri K, Rezaeian S, Delpisheh A. Congenital hypothyroidism screening program in iran; a systematic review and metaanalysis. Iran J Pediatr. 2014;24(6):665-72.

21. Meier $C$, Staub JJ, Roth CB, Guglielmetti M, Kunz M, Miserez $\mathrm{AR}$, et al. TSH-controlled L-thyroxine therapy reduces cholesterol levels and clinical symptoms in subclinical hypothyroidism: a double blind, placebo-controlled trial (Basel Thyroid Study). J Clin Endocrinol Metab. 2001;86(10):4860-6.

22. Agrawal P, Philip R, Saran S, Gutch M, Razi MS, Agroiya $P$, et al. Congenital hypothyroidism. Indian J Endocrinol Metab. 2015;19(2):221-7.
23. Ordooei M, RABIEi A, Soleimanizad R, Mirjalili F. Prevalence of permanent congenital hypothyroidism in children in Yazd, Central Iran. Iran J Public Health. 2013;42(9):1016-20.

24. Korada M, Kibirige M, Turner S, Day J, Johnstone H, Cheetham T. The implementation of revised guidelines and the performance of a screening programme for congenital hypothyroidism. J Med Screen. 2008;15(1):5-8.

25. Jones JH, Mackenzie J, Croft GA, Beaton S, Young D, Donaldson $M D$. Improvement in screening performance and diagnosis of congenital hypothyroidism in Scotland 1979-2003. Arch Dis Child. 2006;91(8):680-5. 